\title{
Analysis of teaching resources used in EFL classes in selected Ecuadorian universities
}

\author{
Hazel Acosta* and Diego Cajas \\ Undergraduate Degree Progam in English Teaching, Faculty of Education, Universidad Nacional de Educación, \\ Azogues, Cañar Province, Ecuador
}

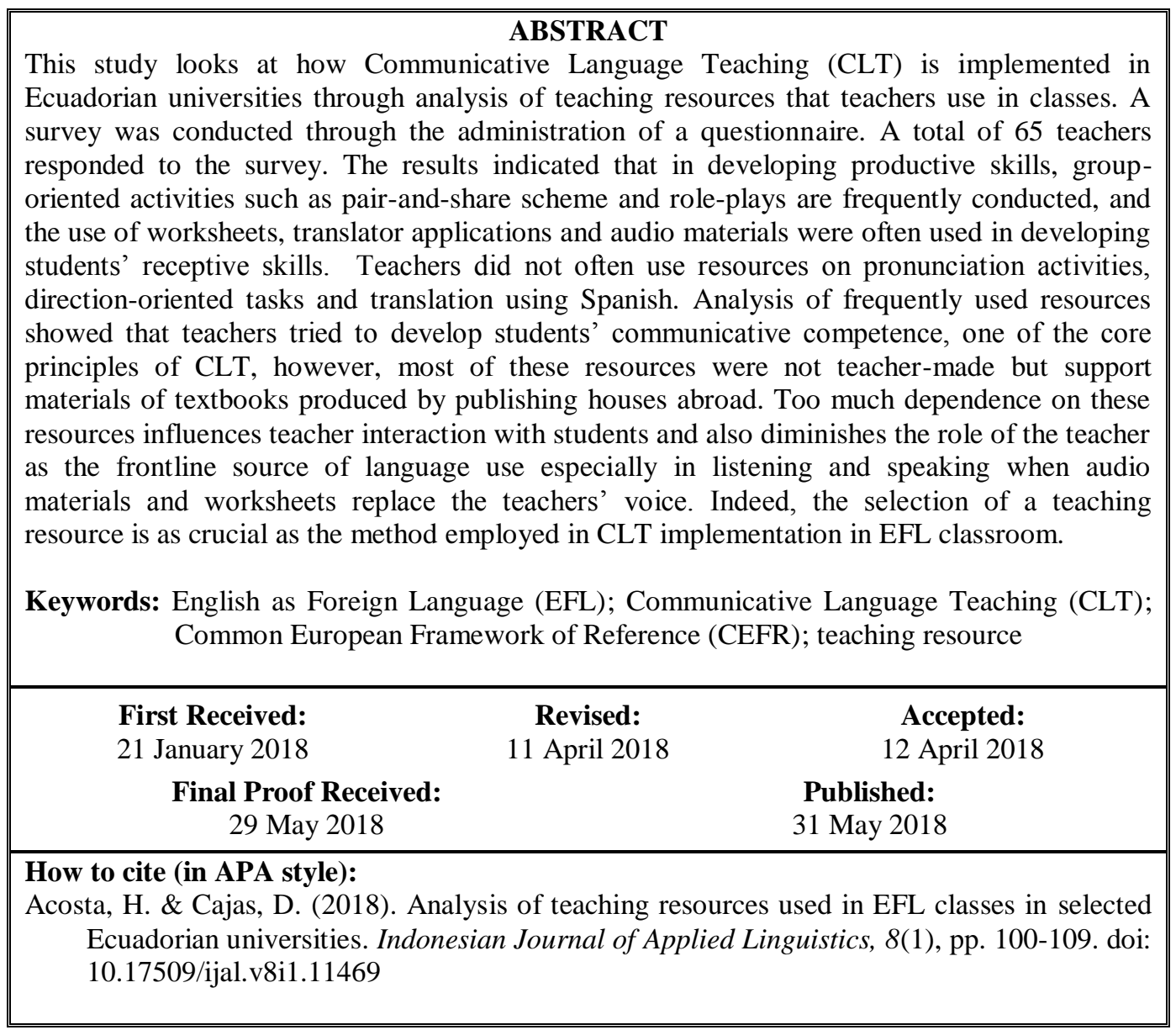

\section{INTRODUCTION}

The use of the Common European Framework of Reference (CEFR) for Languages is one of, if not the most, the widely adopted language frameworks in Ecuador (p. 20), Chile (p. 20), Colombia (p.15) and Mexico (p. 15) based on the comprehensive report of the British Council Education Intelligence (2015) which consists of individual, separate profiles on English language policy at work in these countries. This is due to the legal requirement of government higher education institutions of these countries to require schools and universities to teach English as foreign language. For Mexico, Argentina, Brazil, Colombia, Ecuador, Chile and Peru, 'English is a priority and a concern in all seven countries' (British Council Education Intelligence, 2015, p. 2) and this reflects the intention of these countries to, somehow, leapfrog in their development trajectory and join in the bandwagon of globalisation and internationalisation. While these countries share common goals in their plan to boost economic competitiveness and equip their population a certain level of proficiency in English, they are similar and, likewise, different in their mechanisms and strategies in teaching English as Foreign Language (EFL) in their educational institutions. The adoption of frameworks like the CEFR and the use of specific teaching approaches to achieve the desired learning outcomes are essential components to improving 
English language teaching. However, when teachers have insufficient knowledge about teaching approaches like the Communicative Language Teaching (CLT), the implementation at the classroom level may not be effective. Students may not understand and learn well; thus, nothing significant is achieved in improving instruction. Based on the report of Cronquist and Fiszbein (2017, p. 3), 'English proficiency is very low' in the Latin American region. Analysing how a teaching approach is implemented in the teaching-learning process is key in identifying the factors that impede and facilitate effective learning of English. It is worth knowing whether or not an approach like the CLT is well understood and put into practice in the classrooms.

Ecuador is one of these seven countries that have been in the frontline of EFL implementation in all levels of education. In its efforts to teach English from a clear and well-founded basis, most universities and the Ministry of Education, the office in charge of basic education to children age 6 until 17 years old, have referenced the CEFR as framework for curricular planning and implementation. Students' progress and promotion is denoted by advancements in levels from A1 to B2. In higher education, majority of universities require students to achieve $B 2$ level before a degree is conferred to them. In public schools, the Ecuadorian government has made it mandatory to teach children English in the second grade hoping that after 12- year completion of basic education, they would reach B1 level. The offering of English based on the CEFR is not exclusive to formal education. Many institutes and technology schools also offer English in an attempt to increase students' employability when they finish their course or program. There are also companies that offer short training in English to students who are interested to improve their level before entering the university. Generally, English is considered a priority among foreign languages taught in Ecuador and the view that it is a globalising tool justifies the need to teach it to its students. The 'CEFR emphasizes learners' communicative needs' (p. 14) where 'tasks and interaction' (Cambridge ESOL, 2011, p.14) characterise content delivery and where communicative language teaching (CLT) is its overarching approach. According to Richards and Rogers (1986), the goal of CLT is communicative competence (cited in Li, 1998, p. 678), which is aimed at developing learners' ability to use English in real life settings. Most universities in Ecuador view the development of communicative needs as primal in teaching English. If students can converse and can integrate the four skills - reading, listening, writing and speaking, grammar and structure are just secondary. CLT has become so popular that it has become the teaching mantra of almost every English teacher.

\section{Views, Understanding, and Implementation of CEFR in Ecuador}

The release of Article 124 of the Higher Education Law (Higher Education Council, 2012) was the impetus in the teaching of foreign language as a requirement for graduation in Ecuadorian universities. All language centres of universities must require their students to achieve a 'sufficiency' level of proficiency in a foreign language either as part of their academic curriculum or extracurricular course. They were compelled to identify a foreign language that they could offer to their students, and among foreign languages taught in Ecuadorian universities, English has always been the preferred choice.

In their attempt to base their decisions on an established framework, language policy implementers in the country have adopted the scales of the CEFR as parameter of placement, assessment and promotion of students (Article 31 of the Academic Regimen Regulation, Higher Education Council, 2014). University language centres use level descriptors where a descriptor is divided into two and each level corresponds to a semester. When a student is promoted after a semester, it is assumed that one level descriptor is achieved.

The implementation of the CEFR in Ecuador is prescriptive in a lot of aspects. First, the implementing guidelines which were released by the country's network of language directors or RANI suggested that the implementation of the CEFR is to be conceptualised in a structured manner with specific number of hours and courses or levels. Universities are advised to develop their EFL curriculum around a list of topics, which is often derived from units of a textbook. Second, most universities, by practice, select publishing houses that offer a complete package with contents that correspond to the achievement of CEFR levels. Adherence to the contents and activities of the books are highly encouraged, and, in most cases, required. Third, assessments of students' learning outcomes are either based on the prepared exercises of books or they are required to take international standard tests such as the TOEFL and IELTS before completion of their degree.

The history of the popularity and widespread use of the CEFR in Ecuador is not well documented due to lack of research data. There are two possible reasons why CEFR has become like a 'household name' in EFL language policy. First, there seems to be lack of experts in EFL in the country who can formulate EFL policies and frameworks tailor-made to Ecuadorian context. Second, most Ecuadorian universities are dependent on imported books in teaching English. Publishers of these books guarantee directors that the conceptualisation of its contents, learning outcomes and assessment are based from the CEFR and its level descriptors; but the context and the learning environments of any country where these materials are used are not considered.

The use of CEFR in Ecuador has benefited universities. First, the CEFR has reference level descriptors that serve as guide in determining the desired level of proficiency that a student who is learning English is expected to achieve. Second, clear descriptions of proficiency levels such as B1, for example, inform authorities and teachers that 'students 
must understand the main points of clear standard matters regularly encountered in work, school, leisure, etc.' (Council of Europe, 2001, p. 24). Third, the levels of proficiency of the CEFR allows for a progressive promotion of students from one level to the next. This facilitates easy categorisation and placement of students; although, there is no standard practice that universities follow in promoting students from one level to the next. Some universities use teacher-made tests, others conduct standard tests (FCE, KIT, PEP, etc.), and some copy tests from books. The specific levels of the CEFR have made it easy for universities to set the target level of proficiency because they do not have to formulate by themselves what they consider competencies that students need to develop to reach a certain proficiency level in a specific semester.

There are challenges, however, in the implementation of the CEFR among language centres in the country. Majority of students who finish universities do not seem to have the required B2 level. There is no national study that has been conducted about students' B2 level as universities vary in evaluating students upon completion of their English tuition. Second, evaluation of students does not necessarily target the required level in four skills. Some can read well but can barely speak. Universities are not clear about which skills are or should be prioritised and the assessment and evaluation tools to use to measure the level of proficiency of students.

Another challenging aspect in looking at CEFR as reference is the implementation of Communicative Language Teaching (CLT) as the pedagogical approach. The decision to privilege CLT over other approaches was a collateral effect of the changing discourse in language teaching which gradually moves away from the 'grammar-translation method to the functional/notional approach' (p. 4), and focus, instead, on the 'learners' communicative needs' (p.14), and effective learning through purposeful use of the language (Cambridge ESOL, 2011, p. 14); thus, achieving 'communicative competence' (Al Asmari, 2015, p. 976). Although this approach was introduced in as early as the 1970s (Al Asmari, 2015) to facilitate the easy adaptation of immigrants in English-speaking countries, the CLT has been primarily conceived in an ESL environment while in Ecuador the CLT is implemented in an EFL environment (Al Asmari, 2015, p. 979) while in Ecuador the CLT is implemented in an EFL environment.. It is this type of environment or context that seems to have posed more challenges in the concretization of CEFR through the CLT.

\section{The Communicative Language Teaching (CLT) in Ecuador}

In Ecuador, the use of the CLT in English language teaching is as popular as the CEFR. In universities, the CLT and all methods related to it is the teaching 'mantra' that characterises all planning and implementation in developing English proficiency in higher education. Textbooks and its accompanying resources are conceptualised and planned with the aim to develop the communicative competence of students. Generally, the dispositional learning in EFL teaching in basic education and at the university level is aimed at developing students' ability to interact and communicate in a non-English speaking learning environment. Teaching strategies and aids in a typical EFL classroom is supposedly expected to help a student function in situations that demand the speaking of English; thus, grammar focus is not prioritised. Children are taught to say basic expressions such as 'hello', 'hi', and simple interrogative questions such as, 'What is your name?' The ability of students to utter these expressions during classroom exercises has become indicators that communicative competence is being developed.

In universities, unit planning is followed and the contents in teachers' syllabi are mostly lifted from textbooks' contents. For example, in a low intermediate level or between levels A2 to B1 of most textbooks, learning outcomes that students are expected to achieve at the end of the unit are clearly stated. Each unit has contents that are designed to develop language competence (grammar, vocabulary, and pronunciation), interaction techniques and the four skills (reading, writing, speaking, and listening). Imported books have a well-sequenced list of topics that most teachers copy as content outline in their syllabus. Lesson presentations are primarily reflections of diligent concretisation of the steps outlined in books from motivation phase to the giving of homework.

The seamless guides that textbooks provided to teachers do not, however, come without challenges specifically in implementing communicative language teaching (CLT). Two factors seem to have influenced the implementation of CLT. First, most teachers and administrators consider the CEFR as the curriculum itself and its reference levels are adopted without finding ways on how to produce language-specific reference level descriptions reflective of the learning environment, context and needs of Ecuadorian students. Generally, the classroom is the principal learning environment where students produce the language and interact with their teacher and their classmates; consequently, this lack of diversity of learning environments renders the functionality of language use useless in most cases.

Second, the nature, purpose and use of the CLT as the pedagogical approach of the CEFR is apparently not well understood and interpreted. Third, teachers are required to develop the communicative competence of students but the summative exams at the end of the semester are predominantly grammar-oriented. Fourth, universities are not clear which skills to prioritise. They all believe that students need to have a B2 level in four skills; however, the development of these four skills over a semester varies. Some teachers have a lot of exercises on receptive skills but few in activities to develop productive skills. Thus, at the end of the semester, students can read but could not express 
themselves well by speaking. The ability to speak, however, is a defining characteristic of a learner who can function well in a society due to her supposed ability to communicate with others and produce the language in a functional way. Fourth, the motivation of students who are taking English classes in language centres is generally low due to their pre-occupation of the demands of their degree programs and disinterest to teaching materials. Since teachers mostly follow the steps in the books, most of the reading materials talk about other countries and cultures which students are not interested in. They would rather read a text about the 'Palacio Carondelet' in Quito than about 10 Downing Street in London or the White House in Washington D.C. With learning content, devoid from experience and familiar topics, students do not seem to manifest a strong interest to learn English as a foreign language and this makes the teaching of English as foreign language a lot more challenging.

The use of CLT in Ecuador has been phenomenal. Every teacher talks about it and every administrator tries to adapt it; however, the actual implementation may be near or far from the fundamentals of CLT. However, there is dearth of literature and researches on the implementation of CLT in the country, and there are many ways to explore to determine the nature of CLT implementation in universities such as the teaching methods employed, the EFL policy adopted, evaluation mechanisms conducted, or teaching resources used in classes.

In this study, the identification of teaching resources and techniques that teachers use in developing reading, listening, speaking and writing skills of students are analysed to determine the kind of CLT implementation in universities. Through the analysis of teachers' resources and techniques, insights are brought to the fore as to how teachers understand CLT and its implementation inside classrooms.

\begin{abstract}
METHOD
A survey was administered and 65 teachers responded. Out of 65 teachers, 53 teachers teach in public universities, 11 teachers teach in private universities and 1 teacher teaches in a co-funded university. A co-funded university is a private university but receives funds and support from the Ecuadorian government. The online questionnaire has 20 items with questions that refer to their academic profile and the teaching resources they use in developing the four skills. The survey has three parts: a) academic profile of teachers, b) teaching resources for receptive skills and c) teaching resources for productive skills.
\end{abstract}

\section{FINDINGS AND DISCUSSION}

Academic Profile

Out of 65 university teachers who participated in the online survey, $82 \%$ teach in public universities, $17 \%$ teach in private universities and only $1 \%$ teaches in a co-funded university. Almost half or $43 \%$ have been teaching EFL for 16 years and more, $21 \%$ have taught for $11-15$ years, $25 \%$ have taught for 6-10 years, and $11 \%$ have been teaching EFL for 1-5 years. Among the surveyed teachers, only $2 \%$ have an Ed.D. Degree, $79 \%$ have a master's degree, $17 \%$ of teachers have a bachelor's degree and only $2 \%$ have a teaching certificate at a graduate level.

\section{Use of Communicative Approach.}

Out of 65 teachers, only two teachers believe they do not use the communicative approach in teaching English; thus, they did not proceed to the succeeding items in the survey.

\section{Receptive Skills}

The second part of the survey asked respondents to identify factors that they consider important in conducting listening activities and the frequently used teaching aids that they think help develop students' listening abilities.

Table 1. Factors Considered Important in Listening

\begin{tabular}{llcc}
\hline & Important Factors & Frequency & Percentage \\
\hline \multirow{2}{*}{ Most Important } & Availability of audio materials & $57 / 63$ & $91 \%$ \\
& Size of the class & $32 / 63$ & $51 \%$ \\
& & & \\
\multirow{2}{*}{ Least Important } & $13 / 63$ & $21 \%$ \\
& Availability of a recorder & $15 / 63$ & $24 \%$ \\
\cline { 2 - 3 } & Availability of a DVD player/recorder & 153 \\
\hline
\end{tabular}

The majority of teachers (91\%) consider the availability of audio materials as very important in developing students' skills in listening, and $51 \%$ of the surveyed teachers see class size as equally important to consider. The preference for audio materials, which is usually part of textbook packages, could be attributed to teachers' lack of confidence to demonstrate pronunciation of words. Using prepared audio CDs provide teachers assurance and confidence that students listen to standard pronunciation. This somehow implies that inside the classroom, teachers may not always employ teacher-made materials for listening activities as they may just resort to letting students listen to audio materials included in their textbooks. Interaction between teachers and students during listening activities may be influenced as teachers lose the opportunity to engage students through eye contact, prodding, and feedback.

The use of recorders and DVD players are least factored in due to the influx of information and communications technology (ICT) tools and the existence of speech laboratories. To a certain extent, the infrequent use of recorders, however, deprives students the opportunity to listen, repeat and record words or 
information they have listened to. In CLT, students are encouraged to engage in activities that allow them to learn by familiarising themselves to the sound, stress and intonation of the English language through their interaction with the speakers of the language. Using recorders can be effective for students to record their voices and assess how they fare. Audio recorders also allow students to note their progress from being a pre- basic to an independent user of the language. In most cases, the classroom teacher is the only medium for communication and practice. In cases where teachers often use prepared audios, students' interaction with the language maybe limited and they may not strategically develop communicative competence, or it may take a longer period of time. Table 2 shows the teaching aids that teachers often use in their class.

Table 2. Teaching Aids/Resources Used in Listening

\begin{tabular}{clcc}
\hline & Teaching Aids/Resources & Number & Percentage \\
\hline \multirow{3}{*}{ Frequently Used } & Use of worksheets during listening activities & $42 / 63$ & $67 \%$ \\
& Use of gap-filling exercises during and after listening activities & $42 / 63$ & $67 \%$ \\
& Use of real-life audio transcripts in understanding text & $32 / 63$ & $51 \%$ \\
& & & \\
Least Used & Use of tracing (maps, routes) to understand directions & $11 / 63$ & $17 \%$ \\
& Showing of episodes to introduce sequence and continuity of text & $12 / 63$ & $19 \%$ \\
\hline
\end{tabular}

More than half of the teachers or $67 \%$ use worksheets and ask students to answer gap-filling exercises (67\%) during listening activities. These worksheets are often part of the teacher support materials in imported books that language centres use in teaching English. Having prepared worksheets allow teachers to maximise their time as they do not need to construct their own resources. With prepared worksheets, students get familiar with the text they listen to since it is often based from the readings highlighted in every unit of the textbook; thus, by using the same content, students develop their comprehension in the process. However, frequent use of these resources becomes uncommunicative when routine learning takes places as students are directed to answer worksheets on a daily basis and without meaningful interaction between the text they have listened to and its function with other skills.

Some teachers or $51 \%$ use real-life audio transcripts in introducing text to motivate and encourage students to pay attention to details because the transcript content generally talks about real-life situations. Most audio transcripts have questions that assess students' comprehension, which would inform both teachers and students if they have understood the material.

Teaching aids that are least used in listening activities consist of tracing maps and routes (17\%) and the showing of episodes where students are given tasks $(17 \%)$. The infrequent use of these aids seem to imply that teachers do not always conduct performance-based activities where students are expected to trace routes based on the dictation of the teacher or perform a task based from the episodes they have seen and listened to. These teaching aids are meant to develop students' interaction with the listening material and with their peers and it is one of the strategic techniques that promote CLT. For example, in asking students to trace maps and routes while listening to an audio, students' ability to be sensitive to the sound of the language and understand its pragmatic sense by following instructions are developed. Similarly, the showing of episodes with accompanying tasks develop the ability of students to demonstrate their comprehension of the text they listen to by producing evidence through the completion of the tasks assigned to them.

In general, all teaching aids used whether they are frequently or least employed promote communicative activities inside the classroom. The extent of use of these teaching aids is the factor that influences the implementation of CLT. The consistent use of prepared worksheets and gap filling exercises may render the learning process technical and routine-oriented. As students continually use these aids, students lose the opportunity to interact, imagine the text they listen to and talk about it in their groups. As most of these worksheets and gap-filling exercises are part of the complimentary materials of textbooks, teachers do not construct their own teaching aids; inadvertently, losing the chance to continuously build their capacity to innovate and diversify their materials. The constant use of attached resources from textbooks may not work as learners in classes may not have the same level in their listening skills. As Lochland (2013, p. 262) asserts, the 'one-method-fits-all approach' to English language teaching may not work; thus, the frequent use of textbooks as the main teaching resource limits the use of authentic materials and impedes the responsive approach to planning activities that address students varying skills in listening.

Developing skills in reading help students understand words and develop their vocabulary. In this survey, teachers were asked about what resources they use and activities they conduct in developing students' vocabulary and in aiding them understand meaning from text.

\section{Listening - The most Difficult Skill to Develop}

The survey also asked respondents to identify the skills they think is the most difficult to develop, and teachers consider listening (40\%) as the most difficult skill to develop followed by speaking (33\%), writing (24\%) and reading $(3 \%)$. Based on the data, teachers have difficulty in developing students' listening skills. As native speakers of the Spanish language, students' schema in receiving input through listening is influenced by how syllables in Spanish are spoken. 
When they listen to an input in English, pronunciation is different, as some words in English are not pronounced the way they are spelled. When a teacher pronounces with an accent and when words are uttered fast, listening becomes a challenge to learners.

To facilitate the development of students' listening skills, most of the teachers consider the availability of audio materials and class size as important. The use of audio materials seems to reinforce the view that teachers whose native language is not English, finds security and assurance in these materials which guarantee that students listen to 'correct' pronunciation. However, the tendency to use prepared audio materials may deprive students the opportunity to establish interaction with their teacher. Although the audio material guarantees students precision in pronunciation and enunciation, it may resort to passive listening on the learners' part especially when the class size is big.

A big class size is another factor that teachers consider important in fostering an environment that help students develop their skills in listening. Small size classes allow for more interaction between and among students when they discuss the text they have listened to, unlike a big class size where noise and loud talks interfere students' capacity to absorb and understand what their teacher is saying or what the audio material is talking about. In most Ecuadorian classrooms especially public universities, class size would range from 20 to 40 . Conducting activities that enable students to speak and listen to each other is a challenge especially in a communicative-oriented classroom.

Exposure to language users of the English language is limited in Ecuadorian universities. Being in class, watching movies in English, listening to music in their mobile phones or engaging in conversations with
Americans, British and other foreigners who speak English in town halls, pubs, and other places are few instances that expose students to its use especially how it is pronounced. Inside the university, few teachers from other departments speak English and the availability of social spaces such as English clubs or student networks vary among universities. In general, the necessity to learn English has not been firmly established in Ecuador; thus, students learn English to comply with the requirements for graduation. The desire to find ways to listen to any material in English or to engage with a speaker of the language is not strong.

The survey, also, shows that only $17 \%$ of the teachers teach using tracing map to develop simple grammar and only $19 \%$ conduct activities like showing of episodes to develop comprehension after a listening activity is conducted. This reinforces the belief of most teachers that developing listening skills does not have to be focused on structure of the language; instead, it has to be more of an exposure to the sound and intonation of the words. The problems arises when students do not understand what they are listening to because they are not aware of certain discourse markers that signal the flow of discourse and certain temporal sequence of the English language such as 'like', 'you know'.

In CLT environments in the country, speech sounds are not always factored in universities. There is the assumption that students have learned phonetics when they were in elementary. Unfortunately, the teaching of English in the elementary grades has its own pitfalls and there is no guarantee that after 12 years of basic education, students have achieved the independent user level.

Table 3 presents the resources that teachers use in developing vocabulary of students.

Table 3. Development of Vocabulary

\begin{tabular}{rlcc}
\hline & Activities & Number & Percentage \\
\hline \multirow{3}{*}{ Frequently Used } & Guess-meaning from context & $41 / 63$ & $65 \%$ \\
& Use of body gestures and actions in teaching (ex. Adjectives, verbs) & $39 / 63$ & $62 \%$ \\
& Use of games and competitions in remembering words & $27 / 63$ & $43 \%$ \\
& & \\
& Allowing students to mix two languages: mother tongue and English & $7 / 63$ & $11 \%$ \\
Least Used & Using the mother tongue to teach difficult words & $9 / 63$ & $14 \%$ \\
& Emphasis on the use of affixes (prefix, suffix) & $9 / 63$ & $14 \%$ \\
\hline
\end{tabular}

Among activities that develop students' vocabulary, teachers frequently used guess meaning from context $(65 \%)$, use of body gestures and actions in teaching $(62 \%)$ and games and competitions in remembering words $(43 \%)$. Asking students to guess a meaning from context develops their ability to connect the pragmatic meaning of words and how these words function in a sentence without resorting to the use of translators and dictionaries.

The use of body gestures and actions in teaching facilitate easy understanding of students who have a low level. By looking at gestures students associate words with actions and generate more words thus expanding their vocabulary. What these popular activities seem to lack is the use of resources that develop students' sociolinguistic competence. Vocabulary development is strategically attained when students are asked to develop skills that allow them to understand the semantic and pragmatic meaning of words or their combinations. While students may eventually get familiar with the usage of phrasal verbs based on observations and guess-meaning, they may not understand as much as they can if they are not taught to read and infer the meaning and connotation of phrasal verbs in a sentence. As Wilkins asserts (1972 as cited by Li 1998: 678), 'notional and functional categories' and their associated meaning must be developed so students have the 'linguistic means to perform different kinds of functions', and this is specifically relevant when reading skills are being developed. 
The least used activities employed in developing students' vocabulary consist of mixing the mother tongue (Spanish) and English (11\%). The use of the mother tongue only (14\%) and emphasis on the use of affixes (14\%) are activities that are not frequently used in classes. Based on the results, teachers do not seem to use Spanish in teaching English and this implies that translation is not often employed. While this is a good strategy in providing an environment where students are given more exposure to English, this may work well with students who have a good level of proficiency. However, students who have a low level of proficiency may have difficulties in understanding English words, and translation including the use of cognates may serve better.

Understanding vocabulary is associated with understanding the meaning of words. Table 4 shows the frequently used resources that teachers use in aiding student understand the meaning of words to build and expand their vocabulary.

Table 4: Understanding Meaning

\begin{tabular}{rlcc}
\hline & Resources & Number & Percentage \\
\hline \multirow{2}{*}{ Frequently Used } & Translator applications in mobile phones & $48 / 63$ & $76 \%$ \\
& Dictionary & $31 / 63$ & $49 \%$ \\
& The computer and the internet & $30 / 63$ & $48 \%$ \\
Least Used & English books & $6 / 63$ & $10 \%$ \\
\hline
\end{tabular}

In understanding meaning, students often use translator applications $(76 \%)$, the dictionary (49\%) and the computer/internet (48\%). The availability of today's globalising era provides students the technology that does the job faster than classic resources such as the dictionary. Online translation websites can easily translate long paragraphs in Spanish into English within seconds and this has proven to be very helpful in understanding meaning; but, reading skills are not maximised when students do not bother to review the translated text or when they do not analyse whether the translation is almost the same or not as its original meaning, and this is difficult to do because translation skills is needed. With students who have a low level of English, using online translators may eventually delay their capacity to understand meaning due to dependence on automatic generation of words and sentences without consideration of their semantic and pragmatic use. The dictionary (49\%) is often the second resort when there is no access to the Internet.
The use of English books is the least used resource. Looking for meanings in English books may take time as not all have a glossary. On the contrary, this also implies that the understanding and construction of meaning is developed in a more direct manner since students merely resort to online translation applications instead of looking at meaning and constructing their understanding based on the meaning conveyed by different words in a sentence. English books in the survey are not limited to textbooks used in class but they also refer to all types of references such as grammar books, literary works, storybooks and general information books.

\section{Productive Skills}

The third part of the survey asked respondents to identify factors they consider important in conducting speaking activities and the teaching aids they use to develop students' writing abilities. Table 5 shows the preferred activities that teachers employ in developing students' speaking skills.

Table 5. Preferred Activities for Speaking

\begin{tabular}{llcc}
\hline & Activities & Number & Percentage \\
\hline \multirow{2}{*}{ Preferred Activities } & Use of Pair-and-share technique & $24 / 63$ & $38 \%$ \\
& Conduct of Exercises before and after the topic is discussed & $21 / 63$ & $33 \%$ \\
& & $3 / 63$ & $5 \%$ \\
& Teaching of pronunciation and stress & $3 / 63$ & $5 \%$ \\
Least Preferred Activities & Use of prepared worksheets with defined activities & $3 / 63$ & $5 \%$ \\
& Use of listening activities outlined in a book (official textbook) & $3 / 63$ \\
\hline
\end{tabular}

Most teachers conduct pair-and-share technique (38\%) and the giving of exercises (33\%), which are often accompanying resources of textbooks. Activities like Pair-and-Share encourage students to produce language right after a topic is introduced in an environment that allows them to feel comfortable (Richards 2005 as cited by Al Asmari, 2015, p. 976). Students who are not confident to talk in class can practice with their partners to develop language without fear of being subjected to public assessment, and this reinforces interaction with one another in small groups
(Finocchiaro \& Brumfit 1983 as cited by Li, 1998, p. 679). However, pair-and-share technique are susceptible to meaningless interaction especially when tasks are not clearly communicated or in big classes where teachers cannot oversee everybody during exercises; although, Holliday (1994) believes that monitoring is not necessary because students are expected to be immersed in a problem-based context in language instead of just communicating with each other.

The least employed speaking activities consist of the teaching of pronunciation and stress, used of 
prepared worksheets with defined activities and the use of speaking activities outlined in the book at 5\% turnout. The teaching of pronunciation and stress in English is not often taught in most EFL classrooms because teachers rely on prepared audios to do the job. Some teachers feel insecure and uncomfortable in demonstrating and modelling pronunciation because they are not native speakers of the language. Not doing these teacher-driven activities lead to learning environments where students end up interacting with the material and not with the teacher who is in the frontline of contact in a CLT driven classroom. To further develop speaking skills, it is imperative to develop students' reasoning capability and spontaneity in oral expressions. The activities that most teachers use to develop these are presented in Table 6.

Table 6. Speaking: Reasoning and Spontaneity

\begin{tabular}{llcc}
\hline & Activities & Number & Percentage \\
\hline \multirow{2}{*}{ Frequently Used Activities } & Group discussion (ex. Exemplifying, generalising, analysing) & $40 / 63$ & $63 \%$ \\
& Situations (ex. Students may agree, disagree, persuade, convince) & $38 / 63$ & $60 \%$ \\
& & & \\
& & $9 / 63$ & $14 \%$ \\
Least Preferred Activities & Use of cartoon strips (narration of sequence) & $10 / 63$ & $16 \%$ \\
\cline { 2 - 3 } & Speech-related activities (ex. Reciting a poem, oratorical piece & 16 & \\
\hline
\end{tabular}

In developing reasoning and spontaneity in speaking, most teachers use group discussion to exemplify, generalise or analyses texts $(63 \%)$, and some provide situations $(60 \%)$ for students to agree, disagree, persuade or convince. Activities that are least employed consists of the use of visual aids such as cartoon strips (14\%) and speech related activities where students can recite poems or oratorical piece $(16 \%)$.

The use of group discussion to develop students' reasoning skills in speaking is one of the features of CLT; however, when group discussions are conducted in a class of $100 \%$ non- native speakers, students have the propensity to resort to speaking in their native language especially in big classes when teachers can hardly monitor their tasks. As originally conceived, non-native speakers are supposed to interact, converse and reason out with native speakers in actual settings like in the case of immigrants in the 1970s in England. This is one of the faulty views of CLT in EFL contexts and Jenkins (2006 as cited by Lochland, 2013, p. 264) was one of the firsts to assert that the validity of modelling 'language competence on native language ideologies' hardly is actualised when learners interact with fellow learners who may not exert efforts in speaking English during group work. Further, activities in CLT or communicative approach are 'often carried in small groups' (Larsen-Freeman 1986 as cited by Li, 1998, p. 679). In Ecuador, however, class size in universities typically ranges from 30-40 students although it varies among private institutions.

Writing is a productive skill that reflects understanding of meaning and organisation of sentences. The resources that are used in EFL classrooms are shown in Table 7.

Table 7. Writing: Development of Skills

\begin{tabular}{llcc}
\hline & Activities & Number & Percentage \\
\hline \multirow{3}{*}{$\begin{array}{l}\text { Frequently Used } \\
\text { Activities }\end{array}$} & Writing a report (ex. A place visited, a situation witnessed) & $32 / 63$ & $51 \%$ \\
& Use of mind maps for students to write about & $24 / 63$ & $38 \%$ \\
& Narration of incidents (ex. Retelling a news report, following & $23 / 63$ & $37 \%$ \\
& instructions & & \\
& & $9 / 63$ & $14 \%$ \\
Least Used Activities & Expressions-based activities (ex. Use of common expressions) & $11 / 63$ & $17 \%$ \\
& Writing captions of pictures & $11 / 63$ & $17 \%$ \\
\hline
\end{tabular}

Table 7 shows that teachers in universities frequently ask students to write reports $(51 \%)$, use mind maps for students to write about (38\%), and conduct narration of events like retelling a news report (37\%). Activities that are not frequently conducted consist of expressions-based (14\%) exercises, writing captions of pictures $(17 \%)$ and describing objects in class (17\%).

As a productive skill, writing entails that students know grammar, structure and organisation of words. Based on the results, teachers seem to employ activities that allow students to demonstrate their knowledge of grammar and paragraph organisation such as writing reports. Through mind maps, like the use of concepts maps and graphic organisers, students are able to construct their own understanding of concepts by showing the connections between ideas and the related function of different word categories.

Expression based activities are not frequently used in writing because most of the materials teachers use as resource promote formal register. There are expressions in developing conversations but teachers often use them as reinforcement activities from an audio heard. Writing short dialogues, informal conversations, or presentation script is rarely employed. When executed well, expressions based activities are aids that can help students produce language and exhibit communicative competence.

Writing of captions and describing objects are not, likewise, employed extensively because most textbooks have prepared images where students just have to 
choose which description would be appropriate for the image. This suggests that teachers do not always construct their own activities; inevitably, it might have resulted to students who receive but do not necessarily produce and construct the language, and this defeats the very purpose of CLT.

To identify the general resources used in developing the four skills in learning English, Table 8 shows the resources used inside the classrooms.

Table 8. General Resources Used in the Four Skills

\begin{tabular}{llcc}
\hline & Resources & Number & Percentage \\
\hline Frequently Used Resources & Textbooks and its accompanying resources (CD, student's work) & $39 / 63$ & $62 \%$ \\
& Teacher-made resources & $11 / 63$ & $18 \%$ \\
& & $7 / 63$ & $11 \%$ \\
Least Used Activities & Online platform & $5 / 63$ & $8 \%$ \\
& ICT tools (Interactive websites, YouTube discussions, webinar) & $1 / 63$ & $2 \%$ \\
\hline
\end{tabular}

Among the frequently used resources, more than half or $62 \%$ of the surveyed teachers use textbooks and its accompanying resources such as CD and student's workbooks. While the use of textbooks and its accompanying resources save teachers a considerable amount of time dedicated towards preparation, it also provides teachers a certain degree of confidence that everything they teach is correct and proper. Too much dependence on textbooks, however, may deprive teachers the ability to fulfil the very core principles of CLT. By relying on one aid, teachers lose the opportunity to use authentic materials and other resources (Al Asmari , 2015, p. 977). Further, the sole use of imported textbooks in classes may render the teaching-learning process insensitive to the context of students. Lochland (2013) cited various authors such as Brooks (1997) who 'have raised concerns about the insensitivity of ELT methods to the linguistic, sociocultural, and political background of learners in EFL settings' (p. 261) and insinuate the use of 'one method-fits all approach' (Lochland, 2013, p. 262). This insensitivity is reflected through the use of imported textbooks without adjusting its contents and strategies to the needs and contexts of students and depriving teachers to employ their own materials. While it is appropriate to use textbooks, teaching should be more constructed by teachers through well-informed plan that manifests sound consideration of students' situations and teacher preparation.

After textbooks, a teacher-made resource is the second preferred teaching aid (18\%). Its use reinforces the importance of authentic input of language use ( $\mathrm{Al}$ Asmari 2015, p. 977), addresses the sociolinguistic dimension (Richard \& Rodgers 1986 as cited by Li, 1998, p. 678) in promoting communicative competence and adjusting the content to the needs and context of students. Some universities offer online platforms (11\%) for virtual and blended learning where students need to complete specific number of units. In blended classrooms, students meet their tutor a few times in a week to reinforce the activities students accomplish online. Foreign educational companies produce most of these online platforms; thus, the content and activities in most cases are devoid of student's context. As a result, learning may not be relevant due to lack of realistic activities and genuine production of language that are essential characteristics of CLT.

\section{CONCLUSION}

Based on the resources that teachers use, CLT is widely implemented in universities. The use of materials such as pair-and-share activities, group discussion and reallife audio materials encourage practice and interaction in class. There is less emphasis on accuracy and grammar that serve as impetus for teachers to use different activities such as the use of worksheets, games and mind maps. Some resources such as activity sheets on pronunciation and stress, narration of sequence templates and speech-related activities are not frequently used. This implies that while teachers use resources that encourage communicative competence, the competence students achieve may not be sufficient enough to perform well in the four skills. While they are exposed to dynamic activities such as games or real-life audio materials, without input on the right pronunciation and without familiarisation of stress and structure, they may not understand well an audio material. When a fluent and competent speaker of English talks to them, they may not be able to carry a conversation; or, they may not readily pick up the conversations in a movie they are watching.

The use of textbooks with the accompanying set of resources either promotes or decontextualizes CLT implementation in universities. The design of the topics is based from the CEFR levels, and activities are expected to promote CLT in EFL classrooms. Also, teachers' dependence on textbooks from publishers abroad assures teachers and students that contents are error-free and each component of a unit is woven through to integrate all skills. In CLT, the interaction between the learner and the language user is primal. In Ecuador and other countries specifically in Latin America that consider English as a foreign language, the interaction between the two actors is hardly established. Ecuadorian students generally practice inside their classroom with their English teachers and with their texts as their contact to language use. Brown (2007) and Richards (2006) believe that 'interaction between learner and language user' (as cited in Al Asmari, 2015, p. 980) or those native speakers or people who use 
English as second or other language is necessary in meeting the needs of L2 learners. This somehow implies that not meeting this requisite significantly influences the way CLT is implemented, the manner the CEFR is understood, and ultimately the mechanism EFL is taught in the country.

\section{REFERENCES}

Al Asmari, A. A. (2015). Communicative language teaching in EFL university context: Challenges for teachers. Journal of Language Teaching and Research, 6(5), 976-980.

Brooks, A. A. R. (1997). Learning strategies as learning inhibitors for Chinese speakers. (ERIC Document Reproduction Service No.ED411680).

British Council Education Intelligence (2015). Retrieved from https://ei.britishcouncil.org/sites/default/files/latinamerica-research/English\%20in\%20Ecuador.pdf on September 2, 2017.

Cambridge ESOL. (2011). Using the CEFR: Principles of good practice. Cambridge ESOL, 1-48.

Council of Europe. (2001). Common European Framework of Reference for Languages: Learning, teaching, assessment. Cambridge: Cambridge University Press.
Cronquist, K. \& Fiszbein, A. (2017). English Language learning in Latin America. [online] p.3. Available at: https://www.thedialogue.org/wpcontent/uploads/2017/09/English-LanguageLearning-in-Latin-America-Final-1.pdf [Accessed 6 May 2018].

Higher Education Council (2014). Academic regimen regulation. Retrieved from http:www.ces.gob.ec/gaceta-oficial/reglamentos on August 14, 2017.

Higher Education Council (2012) Organic law of the higher education of Ecuador. Retrieved from http://www.ces.gob.ec/descargas/ley-organica-deeducacion-superior.

Holliday, A. (1994). Appropriate methodology and social context. Cambridge, England: Cambridge University Press.

Li, D. (1998). "It's always more difficult than you plan and imagine": Teachers' perceived difficulties in introducing the communicative approach in South Korea. TESOL Quarterly, 32(4), 677-703.

Lochland, P. W. (2013). Moving beyond communicative language teaching: A situated pedagogy for Japanese EFL classrooms. TESOL Journal, 4(2), 261-262, 264 